\title{
Jóvenes, fin de semana y uso recreativo de drogas: evolución y tendencias del ocio juvenil
}

\author{
Julio Rodríguez Suárez*; Esteban Agulló Tomás*; María Silveria Agulló Tomás** \\ *Área de Psicología Social. Facultad de Psicología. Universidad de Oviedo \\ **Universidad Carlos III de Madrid
}

Enviar correspondencia: Esteban Agulló Tomás. Plaza Feijoo, s/n, 33003, Oviedo. Teléfono: 9851041 79. E-mail: estomas@correo.uniovi.es

\section{Resumen}

Objetivo: análisis de la evolución del ocio en los jóvenes, centrándose en los cambios actitudinales y en la aparición de nuevas actividades recreativas. Método: revisión de los datos obtenidos en distintos estudios, especialmente los institucionales (INJUVE, $\mathrm{CIS}$, Observatorio Español de Drogas), sobre la juventud y sus formas de ocio. Resultados: se observa un cambio en el propio concepto de juventud, que incluye cada vez a un sector más amplio y heterogéneo de población. No obstante, el ocio de los jóvenes tiende a una progresiva homogeneización tanto en las actividades como en el lugar -la calle- y tiempo -la noche, especialmente el fin de semana- en que se desarrolla y en el sentido que adquiere. Esta forma de ocio lleva asociado un consumo importante de alcohol y otras drogas ilegales, banalizándose su consumo y dando lugar a la aparición de fenómenos sociales como el "botellón" y la proliferación del consumo de las drogas de síntesis. Conclusiones: la juventud actual percibe estas sustancias como carentes de riesgos para la salud, y además, les atribuyen valor sociogénico.

Palabras claves: jóvenes, diversión, consumo de drogas, tiempo libre, percepción de riesgos, psicoestimulantes.

\begin{abstract}
Summary
An analysis was conducted of how leisure time in young people has evolved, focussing on changes in attitudes and the emergence of new recreational activities. Data from different psychosocial studies regarding young people and their leisure activities were analysed, particularly institutional ones (INJUVE, CIS, Spanish Drug Monitoring Centre). A change has been observed in the very concept of youth, covering a broader and more heterogeneous sector of the population. However, young people's free time tends to become more homogenous in terms of activities, as well as where (outside the home) and when (at night and particularly, at the weekends) these activities take place and in the meaning they acquire. This form of leisure involves considerable amounts of alcohol and other illegal drugs, dismissing the significance of alcohol and drug consumption, giving rise to social phenomena such as the "botellón" (groups of young people get together in public places and buy alcohol to share. It is less expensive than going to a bar and each one ordering his/ her own drink) and the proliferation of synthetic drug consumption. Conclusions: young people currently perceive these substances as risk-free in terms of their health, in addition to considering them sociogenic.
\end{abstract}

Key Words: leisure, youth, alcohol, psychostimulants, risk perception 


\section{INTRODUCCIÓN}

$\mathbf{P}$ ara analizar la situación en la que se encuentra el ocio de los jóvenes, su evolución en los últimos años y las nuevas tendencias recreativas de este peculiar y complejo colectivo poblacional, hay que dejar muy claro qué es lo que se entiende por juventud, puesto que es éste un concepto que ha ido variando a lo largo del tiempo; además, para que este análisis sea riguroso, es necesario conocer cuál es la importancia real y la significación que posee el ocio para los jóvenes. Y todo esto es lo que haremos en primer lugar.

\subsection{Pero, ¿quiénes son los jóvenes?}

Para empezar, es necesario señalar que el concepto de juventud constituye un concepto en continua evolución; cada época concreta considera jóvenes a un sector de población concreto. La juventud es una etapa del ciclo vital que se sitúa entre la adolescencia y la edad adulta. Por lo tanto, una de sus características definitorias será la franja de edad en que se encuadra a las personas consideradas jóvenes, aunque no es la única; se puede afirmar que la edad es condición necesaria pero no suficiente para definir a los jóvenes. Pero las diferentes franjas de edad en que se delimita la juventud en los diferentes momentos históricos varían de forma considerable, puesto que la juventud constituye un proceso psicosociológico que se transforma histórica y culturalmente. En la actualidad, podemos situarla entre los 15 y los 29 años, aunque el último Informe de Juventud (Martín Serrano y Velarde, 2000) pone de manifiesto que hoy en día se tiende a posponer el tránsito hacia la edad adulta hasta los 34 años. Tal y como indican los autores de este estudio, "por primera vez en nuestras sociedades la juventud dura más tiempo que la infancia." Este hecho se debe a que para dejar de ser joven es necesario alcanzar la emancipación (Zárraga, 1985), entendiendo ésta como el proceso que requiere el cumplimiento de cuatro condiciones: independencia económica (que no solvencia económica), autoadministración de los recursos disponibles, autonomía personal (capacidad de decisión) y construcción de un hogar propio; condiciones necesarias y sólo conjuntamente suficientes (Agulló, 1997; Navarro y Mateo, 1993; Zárraga, 1985). Dada la naturaleza propia de este grupo de población, la juventud como categoría sociológica uniforme no existe. Será, entonces, más pertinente hablar de "jóvenes", en plural, que de “juventud", en singular.

Por tanto, y para concluir, definiremos a los jóvenes como esa realidad compleja y heterogénea, formada por distintos grupos, pertenecientes a estatus socioeconómicos diferentes, con trayectorias y construcciones de identidad diversas (Agulló, 1997), que, habiendo superado fisiológica y psicológicamente la edad adolescente, y reuniendo, por tanto, las condiciones necesarias para desempeñar las funciones propias de los adultos, carecen de las condiciones suficientes para independizarse de su familia de origen, organizando su propio grupo doméstico (Zamora Acosta, 1993).

\section{2. ¿Qué es el ocio y por qué tiende a aso- ciarse siempre con la juventud?}

En una definición lo más condensada posible, entendemos el ocio como toda actividad placentera, elegida voluntariamente en el tiempo de no-trabajo (ver Rodríguez y Agulló, 2002, para una explicación más extensa). El hecho de que la mayoría de los jóvenes carezca de trabajo nos explica por qué el ocio se asocia siempre a estos colectivos. Aun asumiendo que la asistencia a clase y las tareas propias de los jóvenes que son estudiantes sean equiparables al trabajo de los adultos, éstas ocupan un espacio temporal y unas responsabilidades mucho menores que las de aquellos. Los jóvenes españoles valoran el tiempo libre como un elemento fundamental en sus vidas (Rodríguez, 200; Rodríguez y Agulló, 2002), mostrando mayor satisfacción en la forma en que disfrutan su ocio (87\%) que en la que disfrutan su trabajo o estudios (65 y $60 \%$ respectivamente) (CIS, 
1999). A esto puede añadirse que los jóvenes dedican a actividades de ocio en torno a dos tercios de sus ingresos semanales, gastando la mayor parte en salir $(60,3 \%)$ y, en menor medida, en ir al cine (12,8\%), en compras diversas (ropa, libros, música) y en deporte (3\%) (INJUVE, Sondeo periódico de opinión y situación de la gente joven, tercer trimestre 2001).

Los adolescentes y jóvenes de finales de los años noventa perciben el mundo de una manera muy diferente a la manera en que lo hacen los adultos (Elzo, 1998). Una de las diferencias fundamentales se da en la concepción del ocio. Los jóvenes, por lo general, disponen de menos deberes que los adultos, lo que configura el ocio como un espacio fundamental en su vida, siendo, en muchos casos, tan importante como lo es el trabajo para los adultos. Esto significa que existe una centralidad del ocio en los grupos juveniles; centralidad bien conocida por los poderes económicos y que, bajo ningún concepto, puede ser obviada. De esta forma, será en el ocio donde los jóvenes puedan sentirse realizados, afianzando su identidad tanto personal como colectiva, pues no debemos olvidar que el joven realiza su aprendizaje por medio de un proceso condicionado socialmente a través la cultura (Salazar, 2000), y esta cultura es, en buena medida, una cultura del ocio, del entretenimiento y del disfrute (aunque, como veremos, también del consumo).

\subsection{Unos primeros datos para situarnos}

Presentamos a continuación una serie de datos estadísticos de la población juvenil que nos van a permitir sentar las bases para el correcto análisis del empleo del tiempo libre por parte de los jóvenes. La población de entre 15 y 29 años se estima en poco menos de la cuarta parte del total de la población española. La emancipación es un proceso que tarda en alcanzarse; a los 25 años, sólo el 32 por ciento de la gente joven está emancipada económicamente, mientras que el porcentaje aumenta al 72 por ciento a los 29 años. Este hecho es el principal causante del progresivo retraso en la edad en la que los jóvenes salen del hogar para constituir una nueva familia, y viene dándose desde 1990. Es por ello que la familia ocupa un lugar central en la vida de los jóvenes. En la actualidad, la edad promedio para irse de casa son los 26 años, mientras que, como consecuencia de que inician antes la vida en pareja, las mujeres se emancipan antes que los hombres. De Miguel (2000) concluye, en su estudio comparativo de los jóvenes españoles de los sesenta y los de final de siglo, que la diferencia más notable es que en los años sesenta cualquier joven aprovechaba la menor oportunidad para abandonar el hogar familiar, mientras que, cuarenta años más tarde, la mayor parte de los jóvenes sigue viviendo con sus padres y no se ha planteado seriamente la posibilidad de emanciparse. Sin embargo, los datos demuestran que la mayoría de los jóvenes optaría por la independencia de sus padres si realmente pudiesen, si la situación sociolaboral les fuera más propicia. En cualquier caso, este retraso general en la edad de abandono del hogar implica, como es evidente, que sean menos los jóvenes que viven en pareja, lo que repercute, asimismo, en el descenso de la natalidad. Otro dato significativo es que, aunque la proporción de estudiantes universitarios ha ido aumentando paulatinamente, tan sólo el 18 por ciento de los jóvenes españoles (de 15 a 29 años) cursa estudios en la Universidad. Finalmente, parece que la sensación de incertidumbre que les genera el futuro, unida al escaso control percibido sobre el porvenir, ha llevado a los jóvenes a situarse en posiciones más escépticas en cuanto a las creencias religiosas, aumentando el número de los no creyentes y los indiferentes. Además (o por ello), hoy son más que hace unos años los jóvenes que creen, por ejemplo, en el horóscopo (un 33\% frente a un $22 \%$ en 1995). 


\section{JUVENTUDY OCIO EN ESPAÑA: HECHOS Y CIFRAS}

\subsection{Algunas puntualizaciones previas}

De lo dicho hasta ahora se deduce que la disponibilidad de tiempo libre por parte de los jóvenes es mucho más abundante que por parte de los adultos. Como promedio, la juventud dispone de unas 25 horas a la semana para su ocio, superando esta cifra uno de cada tres jóvenes. Se pueden hacer, no obstante, algunas matizaciones al respecto: comúnmente, ese tiempo se va reduciendo a medida que el joven va creciendo, siendo su momento más alto entre los 15 y los 20 años; las chicas disponen de menos tiempo libre, al igual que los jóvenes que viven en un hogar propio, no siendo el trabajo un factor tan condicionante del tiempo de ocio como podría suponerse (y como sí sucede en el caso de los adultos); además, el sector juvenil que está en paro, aunque dispone de más horas de tiempo libre, no parece que dedique este tiempo a la diversión, sino que más bien se presenta como un tiempo desocupado, de apatía y vacío, con el que no tienen más remedio que cargar (Álvaro, 1992; Agulló, 1997).

Por otro lado, no cabe duda de que la familia es un elemento central cuando se es joven. Sin embargo, por lo general, las conversaciones de los jóvenes con sus padres carecen de la profundidad y tranquilidad necesarias para el buen entendimiento, moviéndose entre la excepcionalidad y la banalidad, y generando una comunicación limitada y superficial, sobre todo en las primeras etapas de la juventud (Elzo, 2000).

Es importante señalar la evidente "especialización" en las actividades que los jóvenes realizan en sus casas y fuera de ellas, pudiendo distinguir claramente entre un ocio doméstico, en el que las actividades están relacionadas fundamentalmente con la adquisición y el manejo de información (seguimiento de los medios de comunicación, lectura, conexión a Internet...) y un ocio externo al hogar, en el que las actividades se centran en las relaciones personales, ocupando un espacio importante prácticas como el ejercicio físico y las salidas nocturnas.

Para finalizar, cabe destacar el hecho de que es en sus momentos de ocio cuando los jóvenes se exponen en mayor medida a diferentes riesgos; esto sucede en especial al "salir de marcha" y mantener conductas peligrosas, tales como el consumo de drogas legales e ilegales, el mantenimiento de relaciones sexuales sin medidas preventivas, la posibilidad de verse envueltos en peleas o discusiones, la conducción de coches o motos bajo los efectos del alcohol y de otras sustancias estupefacientes... Pero también están en situación de riesgo al realizar otras actividades de ocio, como sucede en el caso de la práctica de cierto tipo de deportes (fundamentalmente, aquellas actividades de riesgo que han proliferado en los últimos años) o de una utilización nociva de Internet que pueda generar una adicción.

\subsection{La juventud de hoy: ¿a qué dedica el tiempo libre?}

Aunque con lo dicho hasta ahora ya hemos empezado a hacernos una idea de hacia dónde dirigen los jóvenes de hoy su ocio, aún son muchos los datos que podemos ir considerando. De hecho, uno de los problemas con que nos encontramos a la hora de analizar los comportamientos de la juventud es lo que Aguilera (2002) ha denominado mordazmente, para el caso específico del consumo de alcohol juvenil, como la "borrachera de datos" existente, que nos puede llegar a desbordar, dada su magnitud y a tenor de la gran cantidad de estudios de todo tipo realizados por los más variados autores y las más variopintas instituciones. No resulta sencillo comparar con exactitud cifras provenientes de diferentes investigaciones, ya que, en muchos casos, se utilizan procedimientos diferentes para obtener la información, los sujetos analizados tienen sus propias peculiaridades, o las franjas de edad de los jóvenes a los que se pretende estudiar son diferentes. Por ello, para analizar las distintas activi- 
dades que los jóvenes realizan en su tiempo de ocio hemos utilizado principalmente el último Informe de Juventud, realizado por Martín Serrano y Velarde (2000), añadiendo, cuando así lo exigió la situación, algunos datos recogidos por otras publicaciones recientes (Aguinaga y Comas, 1997; Ruiz Olabuénaga, 1998; Elzo y colaboradores, 1999; CIS; 1999, 2000; Hernán, Ramos y Fernández, 2002; los diferentes sondeos periódicos de opinión y situación de la gente joven del INJUVE; etc.).

En la actualidad, las actividades preferidas de los jóvenes son, por este orden, salir con amigos, ver la televisión, escuchar música, hacer deporte, ir al cine, leer libros, dormir/descansar, no hacer nada y viajar. Veamos éstas y otras prácticas recreativas juveniles pormenorizadamente.

Salir con los amigos se presenta como la actividad preferida de los jóvenes. Un joven está en permanente contacto con sus iguales, tanto en los ambientes educacionales (instituto, universidad,...) como en los contextos lúdicos. La libertad de estar con los amigos supone para el joven un contrapeso a la sumisión familiar; es un acto voluntario que, al tiempo de otorgarle un espacio propio, le permite conformar su identidad individual y social. Salir con los amigos constituye una actividad social que suele ir acompañada de otra actividad secundaria, como ir a tomar algo, jugar una partida de cartas o ir al cine. Las cafeterías, los bares, los restaurantes o la calle son lugares habituales donde los jóvenes se citan para pasar las horas en compañía, bromeando y conversando.

Por el contrario, el seguimiento de los medios de comunicación, especialmente de la televisión, está más ligado a la alienación y la inactividad, llenando en muchos casos el hueco de las horas vacías. Los jóvenes no suelen mantener una actitud demasiado crítica hacia los medios de comunicación. Sin embargo, pese a realizar un uso masivo y continuo de la televisión, la juventud le dedica a este medio menos tiempo que cualquier otro segmento de la población. Por los contenidos de las secciones y los programas más seguidos se aprecia en los jóvenes un interés por la recreación y por mantenerse informados, percibiéndose un carácter más selectivo por parte de las mujeres. A la hora de escuchar la radio, los jóvenes se decantan por los programas musicales y, con menor frecuencia, por los programas deportivos, nocturnos e informativos. El porcentaje de jóvenes que sigue la prensa escrita es ya bastante menor, y se acrecienta a medida que aumenta su edad, como es lógico, pues, por el propio proceso de maduración, crece el interés por la información, por conocer lo que sucede dentro y fuera de su país. Aunque los más jóvenes son los que menos leen la prensa, son el grupo que la valora en mayor medida, por lo que representa el grupo más influenciable.

La lectura ocupa un lugar secundario en las preferencias juveniles lúdicas. Hasta los veinte años, los jóvenes leen, sobre todo, ciencia ficción, poesía y novelas de aventura, de acción y policíacas. Más tarde van apareciendo diferencias entre los gustos según se va conformando la personalidad de cada joven. Las chicas se muestran más selectivas y reposadas en sus lecturas, decantándose especialmente por las novelas, al tiempo que los chicos prefieren los temas de actualidad.

Al igual que sucede con la lectura, otras actividades de carácter cultural, como las visitas a museos y exposiciones o la asistencia a conferencias, se incrementan a medida que aumenta la edad de los jóvenes, aunque bien es cierto que un joven que carece de un hábito de lectura resulta muy difícil que llegue a adquirirlo con los años.

Al mismo tiempo que utilizan la radio para escuchar música, los jóvenes hacen uso, con bastante frecuencia, de cintas y discos compactos con el mismo objetivo. Además de conformar un objetivo imprescindible para los sellos discográficos, la juventud actual consume música por otras vías menos lícitas, como la compra de discos piratas o la obtención de música a través de Internet (actividad que, realizada prácticamente en exclusiva por gente joven, está poniendo en jaque a la industria discográfica). Asimismo, la asistencia a conciertos, aun siendo una práctica esporádica, es una de las prácticas lúdicas 
más representativa de la juventud. Y es que no hay que olvidar que la música, con todos sus componentes (directos e indirectos) y representaciones, es uno de los elementos más importantes de los que dispone el joven para construir su identidad, lo que hace que se sienta representado por la música y, en muchos casos, que se sienta representante de un estilo musical concreto; esto ha sido siempre uno de los elementos primordiales a la hora de la constitución del grupo juvenil, sobre todo en lo referente a las tribus urbanas (el rasta, el surfero, el bakaladero... se identifican principalmente por su gusto musical, que conlleva una determinada forma de vestir, pensar y actuar).

El cine, con la televisión, conforma el mundo de imágenes en el que vivimos, la cultura de imágenes tan arraigada hoy día, si bien su práctica es más activa que la de ver televisión, pues conlleva una serie de características de acción y relación que aquella no posee, como un desplazamiento o un gasto en el momento de su utilización. Esta es una de las razones que explican por qué, aunque la mayor parte de los jóvenes declara su interés por el séptimo arte, no acaba de ser una práctica demasiado frecuente. No obstante, las salas cinematográficas siguen nutriéndose fundamentalmente de los colectivos adolescentes y juveniles. El teatro sigue siendo, sin embargo, un espectáculo muy poco frecuentado por los jóvenes.

Por el propio dinamismo juvenil, el deporte constituye una actividad característica de este sector poblacional, cuya práctica es realizada con el fin de divertirse (en opinión del $46 \%$ de los jóvenes) y de hacer ejercicio $(36 \%)$, atribuyendo a la falta de tiempo $(44,5 \%)$ y a la pereza $(30,9 \%)$ el no hacerlo más a menudo. La práctica deportiva es significativamente superior entre los jóvenes de 15 a 17 años y entre los varones. Las chicas llevan a cabo una mayor variedad de deportes, realizando otras actividades beneficiosas para su salud; las jóvenes practican más actividades como la gimnasia (actividades en gimnasios), la natación o el atletismo, todos ellos deportes de práctica individual. El deporte más practicado por los chicos, con diferencia, es el fútbol, y, tras él, el baloncesto, el atletismo, y el ciclismo. Por otro lado, mientras que los padres juegan un papel fundamental para que el joven adquiera hábitos deportivos, los amigos lo hacen para su mantenimiento.

El asociacionismo juvenil, por su parte, contradice en cierto sentido el individualismo y pragmatismo con el que se relaciona a los jóvenes de hoy. La participación de los chicos y las chicas en asociaciones de voluntariado parece estar en crecimiento $y$, en general, la aceptación de este tipo de movimientos sociales es bastante alta. Sin embargo, la participación asociativa en su conjunto no es demasiado elevada, pues siete de cada diez jóvenes no pertenecen a ninguna asociación, si bien dos de cada tres sí que han estado asociados alguna vez en su vida. Los que lo hacen buscan actividades asociativas más variadas que otros sectores de la población, siendo la edad de los jóvenes un factor fundamental, pues los intereses asociativos guardan una estrecha relación con las distintas etapas de la vida juvenil. En cualquier caso, las asociaciones deportivas siguen siendo las que en mayor medida movilizan al colectivo juvenil, sobre todo a los varones, seguidas de las recreativas, culturales, y, ya en menor medida, de las religiosas y asistenciales.

Viajar se ha convertido en una de las actividades preferida por los jóvenes; sin embargo, por su propia idiosincrasia, el turismo es una práctica de realización esporádica, que suele estar en función de la capacidad económica de quien la practica o desea practicarla; de hecho, es la actividad de ocio que los jóvenes, en un mayor porcentaje, dejan de hacer por falta de dinero $(39,5 \%)$. Muchos jóvenes aprovechan las vacaciones para hacer viajes con sus amigos o parejas a diferentes lugares; tanto los destinos, como la naturaleza del viaje van a estar en función de su capacidad económica. En general, los más jóvenes, en principio con menor disponibilidad de dinero, tienen una actitud todoterreno, yendo de un lugar a otro con la mochila al hombro y la tien- 
da de campaña dispuesta, mientras que, a medida que aumenta la edad, el turismo tiende a ser más acomodado. El 43 por ciento de los jóvenes afirma haber salido al extranjero para estudiar, trabajar o hacer turismo (esta proporción se ve aumentada en los estudiantes universitarios hasta casi un $80 \%$ ).

Otra práctica juvenil muy unida a la de salir con los amigos es el esparcimiento nocturno, que se presenta como una de las actividades más características de la juventud; un 65 por ciento de los jóvenes españoles sale todos o casi todos los fines de semana, socializándose en las largas noches sin el control de los adultos, tratando de disfrutar del aquí y el ahora (Laespada y Salazar, 1999). Será entonces cuando tomen contacto con el alcohol y las drogas ilegales, haciendo de su consumo una pauta imprescindible de las salidas nocturnas. Hoy en día, el uso recreativo de drogas legales e ilegales por parte de los jóvenes no puede entenderse como un comportamiento marginal o clandestino, sino que, como hemos señalado con anterioridad, constituye (junto a otros factores como salir con los amigos, vestirse de una manera determinada, adscribirse a un estilo musical concreto, etc.) uno de los elementos que articulan la construcción de su identidad individual, social y cultural (Núñez Pérez y colaboradores, 1998). Prácticamente toda la población juvenil, salvo casos muy concretos, consume alcohol exclusivamente durante los viernes, sábados y/o domingos; este consumo restringido al fin de semana (que será más o menos largo, eso sí, según los diferentes grupos de jóvenes y según la moda al uso), así como a los días festivos, presenta al alcohol como un fenómeno más perjudicial por las elevadas cantidades que se ingieren en esas ocasiones que por la frecuencia de su uso; aunque sea un comportamiento eventual, la gente joven pasa "muchas horas seguidas" realizando actividades de ocio relacionadas con el alcohol (Laespada, 1999). A este consumo de alcohol hay que unir, en muchos casos, el consumo de otras drogas ilegales. Dada la relevancia específica de esta práctica, así como las características propias de esta publicación, al final del capítulo analizaremos más detenidamente el consumo recreativo de alcohol y drogas.

\section{LA EVOLUCIÓN DEL OCIO JUVENIL}

Para analizar la evolución del ocio juvenil en los últimos años en España, hemos recurrido, además de los estudios antes mencionados, a distintos informes de cada época concreta (Zárraga, 1984, 1989; Gil Calvo, 1985; Navarro y Mateo, 1993; Martín Serrano y Velarde, 1997), así como a algunas obras que se dedican específicamente a analizar los cambios surgidos en la población juvenil en este tiempo (Navarro, 1993; Martín Serrano, 1994; De Miguel, 2000).

La configuración actual de la juventud conlleva una serie de incongruencias entre la ontogénesis y la sociogénesis; creemos interesante reproducir aquí la tesis que plantean Martín Serrano y Velarde (2000): “En nuestras sociedades está aumentando la incongruencia entre la maduración biológica y relacional de la juventud y los ritmos de paso hacia la sociedad adulta. Al tiempo que los desarrollos biosociales son más precoces, los procesos de emancipación se concluyen más tardíamente". Esta situación va a tener su repercusión en el uso del tiempo libre por parte de los jóvenes. Así, al tiempo que se adelantan la autonomía para decidir el tipo de ocio que se quiere llevar a cabo, la forma de practicarlo y con quién hacerlo, y la ocupación del tiempo libre fuera del hogar, se atrasa la sustitución del ocio y el consumo adolescente por el ocio y el consumo propios de los adultos.

En los últimos veinticinco años hay una serie de prácticas de esparcimiento que están siempre presentes entre las más señaladas por los jóvenes como las actividades de ocio realizadas con mayor frecuencia. Salir con los amigos es la actividad que ocupa la primera posición en todas las encuestas desde 1977 hasta 1999, mientas que ver la televisión se mantiene desde 1982 en segun- 
do lugar. Escuchar música siempre ha estado en estas primeras posiciones, mientras que actividades como la práctica de deporte han ido adquiriendo relevancia en los últimos años, a costa de otras como ir al cine o la lectura de libros. Esta situación puede observarse detalladamente en la Tabla 1.

Veamos ahora la evolución de las actividades más relevantes. En primer lugar, "salir (o estar) con los amigos" se ha mantenido siempre como la actividad más realizada por los jóvenes, lo cual no debe extrañar, habida cuenta de la importancia que en la juventud suponen las relaciones con los amigos que conforman el grupo de iguales, que permiten romper la severidad de las relaciones familiares. Precisamente, como veíamos antes, es en el hogar donde los jóvenes suelen realizar actividades más sedentarias y alienadas. En este sentido, ver la televisión ha ocupado siempre un lugar predominante. En cuanto a las preferencias televisivas, en los últimos años los jóvenes han ido desinteresándose cada vez más por los programas informativos y de actualidad (entre 1991 y 1999 se reduce a la mitad la proporción de jóvenes que prefieren los informativos), para dejar paso al visionado masivo de películas y teleseries (muchas de las series españolas que han surgido en los últimos años van dirigidas a un público joven), así como a programas de variedades (como "Crónicas Marcianas", programa nocturno, dirigido casi exclusivamente a los jóvenes, que lleva varios años consecutivos liderando las audiencias) y concursos de nuevo formato (como "Gran Hermano", "Operación Triunfo" o "La isla de los famosos"), cuya orientación es claramente juvenil. Como puede verse, muchos de estos cambios están condicionados por las ofertas de las distintas cadenas televisivas.

El número de jóvenes que lee la prensa regularmente viene disminuyendo desde hace ya bastantes años; así, entre los 15 y los 24 años, este porcentaje ha pasado del 45 por ciento en 1984, al 39 por ciento en 1998 (con un $41 \%$ en 1989 y un $40 \%$ en 1993). Una de las razones que puede explicar este descenso es la creciente utilización de Internet, que permite a los jóvenes acceder a la información a través de la red. Dado lo rápido del avance de las nuevas tecnologías, cualquier dato al respecto acaba caducando de inmediato. Un ejemplo claro: Elzo y colaboradores (1999) calculan en un 14,5 por ciento la cantidad de jóvenes que consumen Internet en España, mientras que el Sondeo periódico de opinión y situación de la gente joven, realizado en el segundo trimestre de 2002, habla de un 49,5 por ciento de jóvenes que utiliza Internet (un 49,3\% aunque no lo utiliza sí afirma saber lo que es). La forma más habitual

\begin{tabular}{|c|c|c|c|c|c|c|}
\hline \multicolumn{7}{|c|}{$\begin{array}{l}\text { Tabla 1. Evolución de las actividades realizadas en el tiempo libre. } \\
\text { Orden en el que han sido mencionadas, en años sucesivos. }\end{array}$} \\
\hline & 1977 & 1982 & 1992 & 1993 & 1995 & 1999 \\
\hline $1^{\circ}$ & Estar con amigos & Estar con amigos & Salir con amigos & Estar con amigos & Salir con amigos & Salir con amigos \\
\hline $2^{\circ}$ & Oír música & Ver la T.V. & Ver T.V.-vídeo & Ver la T.V. & Ver la T.V. & Ver la T.V. \\
\hline $3^{\circ}$ & Ver la T.V. & Ir al cine & Oír la radio & Oír música & Hacer deporte & Oír música \\
\hline $4^{\circ}$ & Leer libros & Oír música & Charlar con la famili & Estar con la familia & Leer libros & Hacer deporte \\
\hline $5^{\circ}$ & Ir al cine & Ir a bailar & Ir a bailar & Leer libros & Oír música & Ir al cine \\
\hline $6^{\circ}$ & Ir a bailar & Leer libros & Leer periódicos & Hacer deporte & Ir de excursión & Leer libros \\
\hline $7^{\circ}$ & Oír la radio & Oír la radio & Fumar & Ir al cine & Dormir & Dormir,/descansar \\
\hline $8^{\circ}$ & Hacer deporte & Hacer deporte & Leer revistas & Ir a bailar & Practicar hobbies & No hacer nada \\
\hline $9^{\circ}$ & Ir de excursión & Ir de excursión & Hacer deporte & Ir de excursión & Ir al cine, teatro & viajar \\
\hline Edades & $(15-20)$ & $(15-20)$ & $(15-29)$ & $(15-29)$ & $(15-29)$ & $(15-29)$ \\
\hline
\end{tabular}

Fuente: Informe de Juventud 2000. 
de conectarse a la red es desde sus propias casas $(59,1 \%)$, aunque también se utilizan los accesos de la universidad o el centro de estudios $(30 \%)$ y terminales públicos, como bibliotecas o cybercafés (25\%). La mayoría declara conectarse una o más veces al día. En cuanto a las diferencias por sexos, parece que las chicas utilizan más los servicios de Internet relativos a los estudios y a la obtención de información, mientras que ellos usan la red más a menudo con la finalidad de divertirse o entretenerse. Las actividades relacionadas con la informática son realizadas en mayor proporción en el intervalo de edad de 15 a 17 años. Otro aparato relacionado con las nuevas tecnologías que ha visto disparado su uso en los últimos años es el teléfono móvil. La mayoría de los jóvenes españoles (84\%) dispone de él para su uso personal, utilizándolo con asiduidad tres de cada cuatro jóvenes. Los principales usos están asociados a las relaciones de amistad y, en segundo término, a las relaciones familiares, siendo el envío y la recepción de mensajes la forma más frecuente de utilización.

Por otra parte, los estilos musicales han ido variando con el paso del tiempo, no así el interés juvenil por ellos ni la rebeldía que encierran en su naturaleza muchos de los tipos de música preferidos por los jóvenes. La contracultura que generó el rock en los años sesenta puede compararse a la que en los años noventa significó el bakalao o el rave. El consumo de diferentes drogas acompaña a cada uno de estos estilos musicales. A raíz del citado concurso televisivo "Operación Triunfo", ha resurgido en los adolescentes un fenómeno que tuvo su importancia unas décadas atrás y que parecía olvidado: el fenómeno del fanatismo musical, que ha hecho que por toda España surjan clubes de fans de los artistas que salen del concurso, que ha concentrado a miles de adolescentes y jóvenes en conciertos multitudinarios y que ha desarrollado en los jóvenes una exaltación de la fama y el triunfo como valores importantes en la vida, que sería digna de un análisis minucioso.
Asimismo, desde hace muchos años, la juventud ha ido dejando de interesarse por la lectura de libros (exceptuando los de texto en el caso de los estudiantes), y últimamente este proceso se ha venido acelerando; una explicación posible es la entrada, sino masiva, sí bastante importante, de los ordenadores en los hogares. Las nuevas generaciones han comenzado a sustituir los soportes en los que leen.

Como hemos visto, la práctica de diferentes deportes es una de las actividades que ha ido adquiriendo más popularidad entre los jóvenes con el paso de los años, ayudada, sin duda, por la creación y mejora de diferentes espacios para practicarlos, así como por el ensalzamiento de los beneficios que su práctica supone que se viene haciendo desde diversas instituciones. De un tiempo a esta parte, ha proliferado un nuevo tipo de deporte que tiene en los jóvenes a sus consumidores más habituales y que suele estar ligado al turismo; nos referimos a los denominados deportes de riesgo, actividades realizadas en el medio natural, aprovechando, por lo general, energías libres de la naturaleza, mediante el deslizamiento o basándose en la superación de obstáculos de la propia naturaleza (Olivera, 1995). El concepto de riesgo adquiere una connotación subjetiva, pues supone un peligro que no se sabe en qué momento llegará ni qué consecuencias acarreará. Munné y Codina (1996) destacan el carácter profundamente cualitativo de estos deportes, en los que se experimentan "inéditos estados de conciencia y fuertes emociones, y una percepción de la libertad proporcionada por la flexibilidad de horarios, la ausencia de una reglamentación fija o formal, el reto, la promoción de la individualidad, y el desarrollo de la valía del propio yo".

Por otro lado, en los últimos veinte años, España ha visto cómo el asociacionismo juvenil se desarrollaba enormemente. La evolución ha sido progresiva, si bien hay que tener en cuenta una serie de matices. Durante la dictadura franquista, no existe una pluralidad política ni sindical, potenciándose casi en exclusiva el asociacionismo religioso (Acción 
Católica y el Movimiento Nacional serán los canalizadores de las iniciativas sociales). Linz y Stephan (1996) calculan el número de asociaciones oficiales entre 1933 y 1960 en unas dos mil. La Ley de Asociaciones, promulgada en 1964, supondrá el punto de inflexión que posibilitará la constitución de asociaciones, aunque de forma todavía bastante limitada. En la década de los setenta, la transición democrática permite a los ciudadanos reivindicar la mejora de su calidad de vida a través de diferentes plataformas asociativas. Sin embargo, tras la regulación de la situación política, se produce la paulatina disgregación de los movimientos sociales, dejándolos en manos de los poderes públicos. Entre 1980 y 1985 se produce un receso en la creación de asociaciones, que se va centrando en el voluntariado social, acentuando el compromiso social y la solidaridad como los valores más significativos de este nuevo asociacionismo. Los jóvenes tendrán mucho que ver con este proceso. El Registro Nacional de Asociaciones indica que, durante este periodo de tiempo, se crearon en España unas 66.000 asociaciones voluntarias sin finalidad lucrativa (Prieto Lacaci, 1998). Desde 1988 la participación asociativa se ha estabilizado, si bien es posible que se esté dando un repunte del asociacionismo entre los jóvenes menores de 21 años. Actualmente, ha aumentado la participación en los nuevos movimientos sociales o movimientos de solidaridad. El perfil del voluntario actual nos muestra a un sujeto joven, de clase media, con un aceptable nivel formativo y cultural, que posee un fuerte deseo de intervenir solidariamente y cuya actividad se centra, en la mayoría de las ocasiones, en objetivos de entretenimiento.

El turismo, por su parte, se ha visto beneficiado por la evolución de los medios de transporte y la democratización de su práctica. En la actualidad han aparecido nuevas formas de turismo, como el turismo ecológico (sobre todo el turismo rurah), que tiene en la naturaleza su denominador común y que, en muchas ocasiones, se relaciona con la práctica de los nuevos deportes (Munné y Codina,
1996). Además, desde hace unos años, los grandes festivales veraniegos al aire libre han ido adquiriendo bastante popularidad en nuestro país, como una actividad que mezcla elementos relacionados con el turismo, la música en particular y la cultura en general, el baile y las drogas. No se trata solamente de ir a ver tocar a un gran número de grupos musicales, sino de compartir unos días en compañía de otros jóvenes, en un espacio reservado para ellos, formalizando una especie de cultura de grupo. Festivales como el de Benicássim, que va ya por su novena edición y reúne a unos 50.000 jóvenes cada verano, certifican esta tendencia.

La evolución del uso recreativo de drogas legales e ilegales por parte de los jóvenes es analizada, en un apartado propio, al final del capítulo, aunque podemos avanzar que los cambios en el consumo de alcohol se han dirigido hacia una masificación de su uso recreativo y a un consumo casi total de fin de semana, mientras que las drogas ilegales han evolucionado de forma muy determinante, desapareciendo casi por completo el uso de la heroína y generalizándose el consumo de cannabis, cocaína y drogas de síntesis. Estas últimas sustancias constituyen la mayor preocupación actual dada su divulgación y peligrosidad.

Antes de dar por finalizado este apartado, cabe destacar una curiosa comparativa entre los equipamientos que demandaban los jóvenes en 1985 y los que demandan los nuevos jóvenes diez años más tarde, que nos ofrece el estudio de Martín Serrano y Velarde (2000). Las equipamientos demandados son prácticamente los mismos, no así el orden de prioridades: de solicitar instalaciones deportivas en primer lugar, se pasa a reclamar como primera preferencia cines y teatros, quedando los centros de reunión juvenil en segunda posición y los lugares de diversión en tercera en ambas encuestas. La otra diferencia relevante es que en 1995 se pide la dotación de bibliotecas públicas. La explicación de por qué la demanda de cines y teatros, que en la primera encuesta se situaba en sexta posición, ha pasado a un primer plano, puede 
encontrase en la tendencia actual a acumular las salas cinematográficas en los centros comerciales, que suelen estar situados a las afueras de las ciudades, con la consiguiente reducción, que en muchas ciudades se torna en desaparición, de los cines de barrio.

\section{ALGUNAS CARCTERÍSTICAS DEL OCIO DE LOS JÓVENES ESPAÑOLES}

Pese al carácter heterogéneo que define a la juventud, los españoles jóvenes tienden cada vez más a la homogeneización de sus comportamientos, actitudes y valores. Las grandes multinacionales, los centros comerciales, los medios de comunicación o quienquiera que maneje el rumbo de las modernas sociedades avanzadas las dirigen sin remisión hacia patrones de comportamiento homogéneos en los que el consumo adquiere un papel primordial. Y el ocio se conforma como una de las principales vías, si no la principal, para favorecer esta tendencia a la uniformidad y el consumismo. Veamos en qué modo configura esta nueva situación la forma en que los jóvenes de nuestro país entienden y viven su tiempo de ocio.

\subsection{El ocio consumido: posición ante las nuevas tendencias globalizadoras}

Tal y como venimos señalando, el consumo se presenta como una de las características fundamentales del ocio actual; es el hábito social más difundido, deviniendo no pocas veces en consumo compulsivo o consumismo. La cultura del consumo se produce como consecuencia de las nuevas pautas sociales, del poder de las multinacionales, de lo que Rizter (1996) ha denominado la "mcdonalización de la sociedad", del imperio del centro comercial. La nueva configuración y estructuración del tiempo libre alrededor de "la industria del ocio" (o por decir mejor de "las industrias del ocio"), constituye un fenómeno que afecta a la sociedad en su conjunto, y que concierne específicamente a los jóvenes, dada la centralidad del ocio dentro de su universo vital, así como las características intrínsecas de este colectivo, que se adapta con gran facilidad a las nuevas circunstancias, socializándose a través de estas nuevas pautas de consumo. De hecho, la juventud es el sector de la sociedad a quien en mayor medida van dirigidos los mensajes publicitarios de las grandes compañías; es decir, los jóvenes son los principales destinatarios de los productos y comportamientos de estas industrias del ocio y la cultura, lo que los convierte en los principales protagonistas de esta novedosa forma de vivir. Un estudio realizado en los centros comerciales de los alrededores de Madrid revela que son los jóvenes de 20 a 30 años los que acuden a ellos con mayor frecuencia, con porcentajes de hasta el $46 \%$ en uno de los centros analizados (Gutiérrez Puebla y colaboradores, 2001). Esta situación no ha de extrañarnos, si tenemos en cuenta que los jóvenes interiorizan el modelo propuesto por la cultura de consumo de una forma mucho más profunda que los adultos, lo que hace que estén, en mayor proporción, dispuestos a comprar artículos de lujo, que gasten más de lo que tienen, que obedezcan a sus sentimientos y emociones a la hora de realizar las compras, que tengan menos en cuenta la utilidad del producto, que estén más orientados hacia las marcas y que les encante ir de compras (Orizo, 1996).

La globalización genera individualismo, sentimientos de fragilidad e incertidumbre en los ciudadanos de las sociedades occidentales, siendo esta incertidumbre más acusada todavía en el caso de la gente joven, por su propia idiosincrasia. Esta situación hace que, como demuestran los últimos estudios, los jóvenes españoles actuales tiendan a adoptar actitudes cercanas al "presentismo" (vivir al día, dada la dificultad de proyectarse en el futuro), el pragmatismo y el hedonismo. Los nuevos estilos de vida crean una nueva forma de distribuir el tiempo libre, interviniendo y distribuyendo los espacios (y los tiempos) al antojo de sus necesidades. Los grandes centros comerciales constituyen el paradigma de 
esta realidad; son enormes espacios diseñados para el consumo de productos en los que se presenta una variada oferta lúdica e incluso cultural. Así las cosas, como bien reflexiona María Luisa Setién (1994), "se plantea el dilema de hasta qué punto el ocio actual responde a alguna de las funciones que se le asignan de desarrollo personal, o si, por el contrario, es una fuente de alienación o de evasión dejando de constituir una posibilidad para el desarrollo humano.... Alienación y pérdida de identidad frente a desarrollo personal y fuente de libertad. Ése es, ni más ni menos, el dilema que plantea la realidad del ocio que se impone (que se nos impone). "En el centro comercial uno se siente seguro, a salvo: ni siquiera hay que comprar, lo principal es que estés allí, que te acostumbres a encontrar en ese lugar la posibilidad de que todos tus deseos pueden ser satisfechos $y$, naturalmente, tus deseos bajan mucho de nivel", sentencia Saramago.

Lo cierto es que los centros comerciales han pasado en los últimos años a ocupar un lugar cada vez más destacado como espacios lúdicos en donde los jóvenes pasan parte de su tiempo, realizando gran número de actividades diferentes; y por casi todas ellas han de pagar. Así, en una misma tarde, y en un mismo espacio físico, un joven puede pasear viendo escaparates, ir al gimnasio, jugar a los bolos, echar unas partidas en alguna máquina recreativa, ir al cine (pudiendo elegir entre varias películas diferentes), comer una hamburguesa en un establecimiento de comida rápida... De todas formas, las características particulares de nuestro país, con una amplia tradición en el uso de los espacios públicos de la ciudad para el ocio, con una cultura de barrio, con unas gentes de carácter dinámico y festivo, con la cultura de la calle y el bar de abajo, lo diferencian sustancialmente, ya no sólo de los Estados Unidos, lugar desde donde se importa este nuevo modelo de sociedad, sino también de la mayoría de los países europeos en los que se está imponiendo. De esta forma, cabe esperar que este fenómeno no alcance la popularidad que está alcanzando en esos otros países, aun- que de momento es pronto para saberlo, no es más que una esperanza de quienes esto escriben. No obstante, de los datos que se desprenden de un estudio presentado por Olabuénaga (1998), comprobamos que casi la mitad de los jóvenes prefieren hacer sus compras en tiendas pequeñas $(49,1 \%)$, mientras que el 27 por ciento prefiere los grandes almacenes y el 22,1 por ciento restante los centros comerciales. Estos datos parecen indicar que, en efecto, aún se está lejos del modelo americano, al menos en lo referente a las compras.

Los jóvenes poseen formas de consumir propias y específicas, diferentes a las de los adultos, pero el consumo que llevan a cabo también varía entre unos jóvenes y otros, así como a través de las diferentes etapas que se producen a lo largo de la vida del propio joven, siendo los determinantes de estos consumos factores como la situación laboral, el estado civil, la autonomía, etc. También existen diferencias por género, aunque no se corresponden con la imagen tradicional de despilfarro femenino y practicidad masculina. En líneas generales, los chicos se manifiestan más consumidores que las chicas, y su consumo está asociado en mayor medida a la "posesión de bienes", frente a un consumo femenino más tendente a la "satisfacción de necesidades"; a través del consumo, ellas buscan en mayor medida diferenciarse y ellos igualarse. Con independencia del sexo de los jóvenes, Martín Serrano y Velarde (2000) distinguen entre dos modalidades de consumo juvenil: el consumo que cumple funciones que tienen que ver con sus señas de identidad, caracterizado por un gasto instrumental de aceptación y participación grupal, y relacionado con el tiempo libre y las relaciones con los amigos, y una segunda modalidad de consumo destinada a facilitar su incorporación a la sociedad adulta, caracterizada por gastos e inversiones de utilidad práctica que les proporcionen habilidades sociales y capacidades formativas y profesionales adecuadas a esta finalidad.

En la Tabla 2 puede observarse cómo los propios jóvenes se pagan casi por completo 
los artículos más baratos y personales (anticonceptivos, tabaco, juegos de azar), siendo cada vez mayor la aportación de sus familias a medida que los gastos se relacionan con la asistencia a espectáculos (deportivos y escénicos) y con bienes de mayor valor (coche, moto). Un dato curioso, y que no aparece en esta estadística por haber sido llevada a cabo hace unos años, es que, últimamente, la factura del teléfono móvil se ha convertido en uno de los gastos corrientes de los jóvenes españoles.

En definitiva, podemos concluir este apartado afirmando que el hecho de que exista este ocio consumista viene generado tanto por la ausencia de demandas por parte de los jóvenes, como por la falta de ofertas diferentes por parte de los mayores, de las distintas asociaciones, instituciones, etc.

\section{2. ¿La juventud uniforme?}

Otro dato a tener en cuenta es la tendencia homogeneizadora del ocio juvenil, consecuencia en gran medida de los nuevos estilos de vida que acabamos de analizar. Los jóvenes, en palabras de Aguinaga y Comas (1997), "rehuyen de la diferencia y buscan la distinción"; hacen "lo mismo", de tal forma que conservan su identidad y su integración, pero, al mismo tiempo, lo hacen "de forma diferente", adquiriendo así una marca de clase, una identidad como sujetos particulares. La homogeneidad de sus actividades es cada vez más clara: todos, en mayor o menor medida, realizan las mismas actividades (salir con los amigos, ver la televisión, hacer deporte...) pero dentro de ellas pueden establecer "identificaciones diferenciales" (acudir a bares $u$ otros lugares característicos, ver

\begin{tabular}{|ll|}
\hline \multicolumn{2}{|c|}{$\begin{array}{c}\text { Tabla 2. Proporción de jóvenes que pagan ellos mismos } \\
\text { la mayor parte de los siguientes gastos. }\end{array}$} \\
Anticonceptivos & $97 \%$ \\
\hline Revistas & $96 \%$ \\
\hline Juegos de azar & $81 \%$ \\
\hline Tabaco & $77 \%$ \\
\hline Periódicos & $70 \%$ \\
\hline Excursiones & $69 \%$ \\
\hline Videocassetes & $69 \%$ \\
\hline Discos, Cd's, cintas & $69 \%$ \\
\hline Máquinas de juego & $66 \%$ \\
\hline Conciertos, música & $64 \%$ \\
\hline Bares, cafeterías & $63 \%$ \\
\hline Tebeos & $61 \%$ \\
\hline Discotecas & $58 \%$ \\
\hline Uso de instalaciones deportivas & $57 \%$ \\
\hline Disquetes, juegos de ordenador & $56 \%$ \\
\hline Vacaciones sin familia & $55 \%$ \\
\hline Libros de lectura & $55 \%$ \\
\hline Transporte & $51 \%$ \\
\hline Espectáculos deportivos & $30 \%$ \\
\hline Cine, teatro & $29 \%$ \\
\hline Accesorios, reparaciones coche, moto & $15 \%$ \\
\hline Coche & $8 \%$ \\
\hline Bicicleta & $6 \%$ \\
\hline Moto & $4 \%$ \\
\hline
\end{tabular}

Fuente: JEC. Economía y juventud, 1997. 
unos programas televisivos y no otros, practicar distintos tipos de deporte, , etc.).

Por un lado, y como ocurre en otras esferas de nuestra sociedad, las diferencias de género, fruto de procesos de socialización más igualitarios, cada vez son menores, compartiendo ambos sexos la mayor parte de las actividades y adquiriendo las mujeres un "protagonismo recreativo" que en épocas anteriores pertenecía únicamente a los varones (este salto de la mujer a los espacios antes reservados a los hombres trae consigo, además de la conquista de muchas igualdades necesarias, el acceso a algunas prácticas más peligrosas y desestructuradoras, como el consumo de drogas en el caso concreto del ocio). Al mismo tiempo, la propia configuración de las actividades recreativas que han proliferado en los últimos años, y la preponderancia de la noche como momento de ocio, han hecho posible una disminución en las diferencias según el rango de edad, ya que los más jóvenes han invadido los espacios que antes pertenecían a los mayores, y los mayores cada vez tardan más en dar el paso hacia la vida adulta, compartiendo, por ello, actividades y gustos similares. Por otra parte, los jóvenes pertenecientes a zonas rurales participan de esta homogenización, favorecidos por el descenso de diferencias de equipamientos e información existente entre las ciudades y los pueblos, así como, en muchos casos, por la progresiva facilidad de los jóvenes rurales para trasladarse los fines de semana a las ciudades. Además, en la actualidad, las diferencias por clase social, ingresos o capacidad de gasto no suponen diferencias notables en el perfil de actividades de los jóvenes, mientras que en los adultos sí (Aguinaga y Comas, 1997). Por último, son muchos los estudios que señalan que el ocio de los jóvenes estudiantes apenas se distingue del de los trabajadores, más allá de las inevitables diferencias proporcionadas por la capacidad económica de éstos y la libertad de horarios de aquellos (Rodríguez y Agulló, 1999; Rodríguez, 2000).

Todo esto no quiere decir que no haya divergencias en los comportamientos, actitu- des y valores de estos grupos de jóvenes con respecto al ocio, sino que éstas son menores que en épocas anteriores y que se mantiene una tendencia de reducción de las diferencias.

También resulta curioso que la configuración de las llamadas "tribus urbanas", que tanto impacto llegaron a generar en la investigación sociológica de la juventud, haya cambiado de forma tan radical en tan poco tiempo. Aunque aún permanecen pequeños grupos de "skins" o de "heavies", y todavía se puede uno cruzar con algún "mod", algún "rocker" o algún "punk" desubicado, lo cierto es que la gran cantidad de literatura que el análisis de estos grupos suscitó entre mediados de los ochenta y mediados de los noventa (v.g. Maffesoli, 1990; Encinas Garza, 1994; Costa, Pérez Tornero y Tropea, 1996), ha perdido casi completamente su vigencia. Otras tribus posteriores, como los "grunges", que surgieron a principios de los noventa, tras la estela de un enfant terrible como Kurt Cobain (líder del grupo musical Nirvana), no tardaron, al igual que su gurú, en pasar a la historia. Quizá el grupo, si es que se puede hablar de grupo en este caso, que pervive en mayor número sea el de los "pijos", si bien constituye un colectivo paradójico, pues sus integrantes no poseen una conciencia de grupo, aunque sus ropas de marca, sus gustos musicales, sus diversiones caras, sus colegios de pago, sus formas elitistas de pensar... los conformen como un grupo claramente distinguible del resto.

A los testimonios residuales de estos jóvenes pertenecientes a tribus urbanas surgidas en los ochenta, se unen pequeñas bandas de nuevas tribus también minoritarias, como los "rastas" o "dread locks" (provistos de su pelo enmarañado en trenzas, de su música estilo reggae, de su afición a los porros, aunque desprovistos en su mayor parte del sentido religioso que define a los verdaderos "rastafaris"), o los "bad boys" (seguidores de hip hop, monopatín en mano y spray camuflado para hacer los graffitis), o los "surferos" (melena al viento y tabla de surf de todos los colores). Aparte de estas excepciones, hoy 
en día los adolescentes y jóvenes son menos diferenciables, menos etiquetables, más eclécticos, más homogéneos. Un grupo que cuenta actualmente con más integrantes es el de los "bakaladeros", cuyo nexo de unión es la música (lo que comenzó con el acid house y ha dado paso a la música máquina o música electrónica), la forma de diversión (bailar en grandes discotecas, hacer uso de los locales conocidos como after hours -bares o pubs que abren sus puertas por las mañanas y permiten a los jóvenes prolongar sus noches de marcha hasta el mediodía-) y el consumo de drogas de síntesis. Por otra parte, podemos hablar de un grupo mayoritario conformado tanto por los jóvenes no adscritos a ningún grupo concreto como por los "indies" o "alternativos" (por llamarlos de alguna manera) y que, en cuanto a su forma de vestir, no se diferencian en exceso de los anteriores, si acaso podemos afirmar que son algo más discretos. La verdad es que cada vez hay menos diferencias entre los atuendos y las filosofías de los distintos grupos de jóvenes. Cumpliendo la función que desempeña el uniforme, que te diferencia de unos al tiempo que te iguala a otros, mantienen una estética común (o muy semejante) que les identifica entre ellos, diferenciándolos de los adultos. Con ciertas disparidades, tanto los "bakaladeros", como los "alternativos", como los "pijos" se distinguen por sus pantalones caídos, sus tatuajes (permanentes y temporales), su multitud de pendientes, sus piercings, su calzado deportivo, etc. Hoy día, al hablar de moda juvenil, hablamos de ropas y ornamentos comunes a casi todos los grupos, con pequeños matices diferenciales, que siempre existirán por la confluencia de una suerte de intereses culturales, sociales, económicos, comerciales...

\subsection{La noche como tiempo, la calle como espacio}

Adoptando y generalizando la argumentación que llevan a cabo Costa, Pérez Tornero y Tropea (1996), en su caso para hablar sobre las tribus urbanas, podemos establecer los principales "momentos de identidad" del joven y su grupo, "de su actuación y su pertenencia", a través de la siguiente agrupación: lo cotidiano, el fin de semana y lo extraordinario. Desde este punto de vista, lo cotidiano estaría configurado por el tiempo, poco relevante, que transcurre entre los fines de semana o los acontecimientos extraordinarios. El tipo de actividades que los jóvenes realizan durante este "tiempo de rutina" o "tiempo muerto", que se dispone simbólicamente bajo los designios del dios Kronos, tiene que ver en gran medida con la imaginación de lo significativo, a través de la vivencia de ficciones. Así, ver la televisión, ir al cine, escuchar música, leer, jugar al ordenador o a las consolas de videojuegos, o chatear por Internet son algunas de las actividades más frecuentes durante este tiempo. Por el contrario, el fin de semana se presenta como el momento que, continuando con la metáfora, estará regido por el dios Kairós, permitiendo experimentar al joven la sensación de libertad que se le niega el resto del tiempo, pudiendo expresarse y actuar a su manera y desarrollando su identidad personal y grupal. Si nos atenemos a la importancia que los jóvenes confieren al ocio como parte central de su existencia, y si tenemos en cuenta que es durante los días que componen el fin de semana cuando la mayor parte de ellos busca y encuentra su identidad propia, desarrollando su personalidad a través de actividades, rituales y símbolos compartidos con el grupo de iguales, configurándose como una válvula de escape indispensable alejada de la presencia intimidatoria de los adultos, no nos debe extrañar que el fin de semana dé sentido a la vida de muchos de estos jóvenes. Por último, el tercer tipo de tiempo está conformado por lo excepcional, por esos "eventos especiales" a los que el joven tiene acceso de forma esporádica y que, en muchos casos, son esperados con ahínco durante varios días e incluso meses. Nos referimos a acontecimientos tales como una fiesta, un partido de fútbol trascendente, un festival musical, un concierto de algún grupo exitoso, los carnavales, la nochevieja, un viaje con los amigos o la pareja, etc. Actividades todas ellas, no por menos habituales, menos importantes. Por 
último, a estos tres tiempos se podría añadir una nueva dimensión: la estacionalidad del ocio; algunas épocas del año, como la Navidad, la Semana Santa y, sobre todo, el verano, van a condicionar el tipo de ocio que los jóvenes desarrollan. En Navidad aumenta el tiempo dedicado a la familia y a salir de compras, mientras que la Semana Santa y el verano son tiempos proclives para los viajes, la práctica de deportes, el no hacer nada y la mayor frecuencia en las salidas nocturnas.

Salir por la noche con los amigos, en especial los fines de semana, lo que algunos investigadores denominan "esparcimiento nocturno" y en el argot juvenil se conoce como "salir de marcha", concede a los jóvenes mayores posibilidades de socialización, otorgándoles un sentimiento de autonomía e independencia (del que, como hemos visto, carecen en muchos aspectos y/o ámbitos), e incluso un sentimiento de autoridad, percibiendo la noche como su tiempo exclusivo, y las calles vacías y los bares y discotecas que frecuentan como su territorio. Iglesias de Ussel (1997) especula con que la conquista de la noche se presenta como el único símbolo que perdura de la inserción de los jóvenes al estado adulto, "el único rito de transición". Al hacer suya la noche, al hacer suya la calle, los jóvenes anulan el dominio que los adultos han ejercido con anterioridad sobre sus horarios y sus vidas. Precisamente la calle, al ofrecer mayor visibilidad, al permitir mayor movilidad para potenciar los encuentros interpersonales, y al no obligar a ningún desembolso económico se convertirá en la protagonista de las noches de marcha juveniles (Iglesias de Ussel, 1997). La calle ha adquirido en los últimos años una especial relevancia en el ocio juvenil, potenciada particularmente por el fenómeno del "botellón" (descendiente directo del fenómeno de la "litrona"), cuya importancia creciente nos obliga a tratarlo más adelante con mayor detenimiento. Precisamente esta preferencia de la calle como escenario del ocio juvenil, deja incompleta la puntualización que De Miguel (1990) hacía hace pocos años según la cual los bares (junto a los pubs y las salas de fiestas) se presentan como los lugares de socialización más comunes para los jóvenes. A ellos hay que añadir hoy, sin lugar a dudas, las plazas y calles de la mayoría de las ciudades españolas.

La adopción de la noche como universo propio juvenil se plantea, como veíamos antes, desde el punto de vista de "una ruptura de lo cotidiano", que permite "el comportamiento disociado" de las normas relativas a las relaciones y otros "comportamientos más cotidianos y habituales" (Ruiz Olabuénaga, 1998). La movilidad que tiene lugar en la noche, entre unos bares y otros o simplemente por las citadas calles, es campo abonado para que se produzcan múltiples relaciones interpersonales "efímeras" y "superficiales"; en palabras del propio Iglesias de Ussel, se trata de "crear un sentimiento de intimidad, imposibilitándolo". Sin duda, uno de los factores que más influye a la hora de las salidas nocturnas de los jóvenes es la posibilidad que se les presenta para establecer relaciones con otros jóvenes, resultando evidente la búsqueda de relaciones sexuales, dado que en esos ambientes se generan condiciones propicias para que éstas se produzcan, como son una mayor libertad que en otros entornos y situaciones, un mayor acercamiento físico, propiciado especialmente por el baile, una mayor desinhibición por la ingesta de alcohol u otras drogas, etc.

Tal y como están las cosas, no es posible abordar este aspecto de la vida juvenil sin asociarlo al consumo de alcohol que suele conllevar, ni debemos olvidar tampoco el consumo de otras drogas ilegales que, aunque en menor grado, se registra asimismo en estas situaciones. Este tipo de consumos nocivos, si bien no tiene porque darse durante las noches de marcha, está generalmente asociado a ellas. Estas prácticas se constituyen como "actividades marginales de ocio", representando una de las principales formas de malgastar el tiempo de ocio, poniendo en peligro la salud de los jóvenes. Dada la trascendencia de este asunto concreto dedicamos a continuación un apartado específico al 
análisis de las nuevas tendencias juveniles en el uso recreativo de drogas.

No obstante, antes de ello, debemos hacer un par de reflexiones más. En primer lugar, en los últimos años, se han venido ofertando, a través de la Administración, diversas propuestas alternativas de ocio juvenil, tales como los programas "Abierto hasta el amanecer" (Gijón), "La noche es tuya" (Oviedo), "Todo por la noche" (Fuenlabrada), o "Pacto por la noche" (Extremadura), por citar algunos de los pioneros, que brindan la posibilidad de participar en actividades deportivas, socioculturales y meramente recreativas, fundamentalmente los viernes y sábados por la noche, en distintos locales públicos, como centros municipales, institutos, polideportivos o bibliotecas. Estas iniciativas están planteadas en el horario nocturno de los fines de semana y van dirigidas, sobre todo, a los más jóvenes. Aceptando la importancia que esta innovación ha tenido y tiene como alternativa preventiva de diversión, favorecedora de estilos de vida sanos, creemos que, de momento, no deja de ser algo minoritario, que no va en busca del joven, a los lugares donde éste realiza sus actividades cotidianas de ocio, sino que espera que sea el propio joven quien se acerque a ellas, a sus instalaciones concretas, en los horarios que se establecen, etc. El debate sobre la pertinencia de este tipo de alternativas de ocio está abierto, aunque lo dejaremos para mejor ocasión, pues no es éste el objetivo del presente capítulo (es interesante, no obstante, el que comiencen ya a aparecer algunos estudios al respecto, como el elaborado por Comas, en 2001, para el Instituto de la Juventud).

Por último, cabe destacar que esta asunción de la noche como universo propio juvenil no se reduce a los fines de semana, aunque sea en ellos donde adquiere su expresión más significativa, sino que se prolonga a lo largo de la semana, gracias fundamentalmente a la libertad horaria de la que gozan la mayor parte de los jóvenes. Así, la programación televisiva y radiofónica de las madrugadas se dirige en un alto grado a ellos, que a su vez monopolizan las conexiones a Internet en el horario nocturno; al mismo tiempo, los restaurantes de comida rápida, las salas de conciertos, las cafeterías, los cybercafés, los cines, e incluso las bibliotecas extienden sus horarios hasta horas cada vez más altas de la madrugada, atendiendo a las demandas de la juventud noctámbula.

\section{NUEVAS TENDENCIAS EN EL CONSU- MO RECREATIVO DE ALCOHOL Y DROGAS}

Como venimos insistiendo, hablar de jóvenes y ocio es hablar del fin de semana; y hablar del fin de semana lleva implícito hablar del consumo masivo tanto de alcohol como de otro tipo de drogas ilegales. Los jóvenes, en mayor o menor grado, consumen alcohol de forma masiva y gran parte de ellos ha experimentado con alguna droga ilegal (cannabis, cocaína y éxtasis, fundamentalmente); además, los índices de policonsumo observados entre los consumidores jóvenes son cada vez mayores. Un hecho que no se debe pasar por alto es que, al igual que sucedía en 1998, el riesgo asociado al consumo habitual de tabaco es mayor que el que se asocia al consumo habitual de alcohol y de otras drogas ilegales. No es de extrañar que Bobes y Calafat (2000) muestren su preocupación por "la extensión creciente y la banalización del consumo de drogas" por parte de los jóvenes y por la falta de información contrastada a la que tienen acceso, que hace que muchos de esos jóvenes lleguen a "conclusiones y decisiones erróneas sobre el consumo".

Los datos más fiables sobre el consumo de drogas por parte de los jóvenes son los aportados por el Observatorio Español sobre Drogas, tanto en sus encuestas domiciliarias a la población general, como en las encuestas a la población escolar. Precisamente, de la última Encuesta Domiciliaria sobre Consumo de Drogas en España, 2001, son los siguientes datos esclarecedores (Tabla 3).

Como puede observarse, tanto el alcohol como el tabaco son las drogas más consumidas, seguidas, aunque a cierta distancia, por 


\begin{tabular}{|lccc|}
\hline & $\begin{array}{c}\text { Tabla 3. Proporción de consumidores de algunas sustancias psicoactivas } \\
\text { en los últimos } \\
\mathbf{1 2} \text { meses en los jóvenes de } \\
\text { Hombres }\end{array}$ & Mujeres & 29 años, según droga y sexo. \\
Tabaco & $51,8 \%$ & $50,7 \%$ & $51,2 \%$ \\
\hline Alcohol & $85,1 \%$ & $77,1 \%$ & $81,1 \%$ \\
\hline Cannabis & $25,2 \%$ & $13,8 \%$ & $20 \%$ \\
\hline Éxtasis & $6,8 \%$ & $2 \%$ & $4,4 \%$ \\
\hline Cocaína & $7 \%$ & $2,9 \%$ & $5 \%$ \\
\hline
\end{tabular}

Fuente: DGPNSD. Observatorio Español sobre Drogas, 2001.

el cannabis, la cocaína y el éxtasis, en ese orden; pese a la incorporación progresiva de la mujer a este tipo de consumos, sólo el tabaco, y en menor medida el alcohol, aparecen en proporciones semejantes en ambos sexos, lo cual es debido al fuerte incremento que su uso ha experimentado en los últimos años por parte de la población juvenil femenina; no es de extrañar que las mujeres, en especial las adolescentes, hayan pasado a ser las principales destinatarias de las campañas publicitarias de las compañías alcoholeras y tabaqueras (Navarro, 2000).

Aparte de los numerosos estudios llevados a cabo por el Plan Nacional sobre Drogas, así como de los diferentes informes de juventud, las monografías que esta revista ha realizado en los últimos años sobre alcohol (Gual, A., 2002), cannabis (Bobes y Calafat, 2000) y cocaína (Pascual, Torres y Calafat, 2001) nos brindan un material imprescindible para el estudio riguroso de este fenómeno. Analizaremos a continuación estas tendencias de forma más pormenorizada.

\subsection{El alcohol}

El tabaco y el alcohol son las drogas más consumidas por los jóvenes españoles. En los últimos años, el consumo de alcohol se ha ido generalizando hasta el punto de ser hoy una práctica habitual del ocio juvenil de fin de semana; el alcohol ha dejado de ser un medio a través del que socializarse y afianzar la pertenencia al grupo de iguales, para pasar a ser "un fin en sí mismo" para los jóvenes
(Elzo y colaboradores, 1999). Este hecho lo convierte en un grave problema social. De hecho, el 94,7 por ciento de la población española mayor de dieciocho años cree que el consumo de alcohol empieza demasiado pronto, y el 91,1 por ciento considera que se debería exigir el cumplimiento de las medidas legales vigentes para que los adolescentes no tengan acceso a las bebidas alcohólicas (Barómetro de Marzo, CIS -2002-). El fenómeno del botellón no hace sino acrecentar esta situación, pues a los problemas que conlleva el propio consumo de alcohol hay que añadir la amplia polémica popular que suscita esta práctica, tanto por los ruidos nocturnos como por la suciedad que genera. La inquietud de la sociedad es indudable, si bien no alcanza la preocupación existente por el uso de drogas de síntesis. El 69,9 por ciento de la población española mayor de dieciocho años manifiesta estar preocupada $(42,8 \%)$ o muy preocupada $(27,1 \%)$ por el fenómeno del botellón (CIS, 2002). Los jóvenes que aún no son mayores de edad son conscientes de las facilidades que tienen a la hora de comprar y consumir alcohol (como revela Sánchez -2002-, el 84 por ciento de los escolares españoles afirma que le resultaría fácil o muy fácil conseguir esta sustancia), al tiempo que carecen de la información necesaria o tienden a minimizar las consecuencias que el alcohol puede tener sobre ellos (Pascual, 2002); de hecho, según la Encuesta sobre drogas a población escolar (2001), tan sólo el 7 por ciento de los jóvenes entre catorce y 
dieciocho años percibe que bebe bastante o demasiado.

Secades $(1996,1998)$ observa unas pautas características, diferentes al modelo tradicional adulto, que conforman un modelo propio (manteniéndose con independencia de variables como el nivel de estudios o la clase social):

- Hay una tendencia a la iniciación precoz. Se observa un paulatino descenso en la edad de inicio en el consumo de alcohol; la última Encuesta sobre Drogas a la Población Escolar lo sitúa en los 13,2 años, mientras que la Encuesta Domiciliaria establece esta edad en 16,9 años.

- El consumo es realizado, principalmente, en el fin de semana y en los días festivos, es decir, durante el tiempo dedicado fundamentalmente a la evasión.

- Incorporación de las chicas al consumo de alcohol de forma excesiva (un dato clarificador sobre este aspecto lo encontramos en la Encuesta Domiciliaria sobre Consumo de Drogas de 1999, donde se aprecia un considerable incremento de consumo en el grupo de chicas más jóvenes, de 15 a 19 años, que han pasado, para el indicador "consumo en el último mes", de un 37,7 por ciento en 1995 a un 50,9 por ciento en 1999).

- El consumo de alcohol se realiza fuera de casa (del ámbito familiar), en la calle y en los lugares de relación social de los jóvenes, y en compañía de los iguales.

- Se bebe de forma compulsiva, en busca, sobre todo, de los efectos embriagantes.

- Existe un desplazamiento del consumo de vino al consumo de cerveza y de bebidas combinadas de alta graduación. Entre los jóvenes de 15 a 29 años predomina el consumo de cerveza durante los días laborables y los combinados/cubatas durante el fin de semana.

De lo que no cabe duda es de que en los últimos años se ha producido un cambio en la forma en que los jóvenes beben. La evolución del consumo de alcohol entre los jóvenes desde los años sesenta ha seguido una serie de pautas que Comas (1994) resume a través de tres etapas bien diferenciadas:

- La primera etapa se prolonga hasta los años ochenta, y en ella se produce una expansión del consumo pero continuando con las pautas tradicionales, es decir, siguiendo el modelo de los adultos; es un consumo principalmente masculino.

- La segunda etapa se establece entre 1984 y 1994; en ella los consumos comienzan a masificarse y se va adoptando el patrón de consumo del fin de semana, aunque no se abandonan completamente las pautas tradicionales.

- La tercera etapa coincide con el momento en que Comas presenta su estudio (1994), y en ella, el autor aprecia la existencia de un sector de jóvenes que "reacciona contra el fenómeno, se vuelve abstemio, adopta actitudes personales contra el alcohol, aunque sin articularlas ni social ni políticamente, porque se mueve con la cultura del rechazo pero no de alternativas". A pesar de este grupo, el consumo de alcohol se mantiene estable, debido fundamentalmente a la aparición de otro grupo de "grandes bebedores" que los contrarrestaría.

Desde entonces las cosas han seguido cambiando. Como señala la Encuesta Domiciliaria sobre Consumo de Drogas en España, 2001, actualmente, entre los jóvenes de quince a veintinueve años, el uso e alcohol se centra muy fuertemente durante el fin de semana (viernes, sábado o domingo), estando mucho menos extendido durante los días laborables. Esos días del fin de semana se bebe mezclando bebidas de alta graduación alcohólica. En la Tabla 4 se muestra la evolución de los porcentajes de consumo de alcohol en el último mes desde 1995. Como dato más significativo aparece una estabilidad en el consumo masculino frente a un aumento progresivo del femenino en todos los grupos de edad. 


\begin{tabular}{|c|c|c|c|c|c|c|}
\hline \multicolumn{7}{|c|}{$\begin{array}{l}\text { Tabla 4. Evolución de las prevalencias de consumo de alcohol en } \\
\text { los últimos treinta días, por sexo y grupo de edad. España, 1995-1999. }\end{array}$} \\
\hline & \multicolumn{2}{|c|}{1995} & \multicolumn{2}{|c|}{1997} & \multicolumn{2}{|c|}{1999} \\
\hline Grupos de edad & Hombres & Mujeres & Hombres & Mujeres & Hombres & Mujeres \\
\hline $15-19$ & $56,8 \%$ & $37,7 \%$ & $52,8 \%$ & $46,2 \%$ & $54,9 \%$ & $50,9 \%$ \\
\hline $20-24$ & $75,6 \%$ & $53,2 \%$ & $79,1 \%$ & $60,4 \%$ & $76,5 \%$ & $65,3 \%$ \\
\hline $25-29$ & $77,9 \%$ & $46 \%$ & $76,9 \%$ & $55,1 \%$ & $77,6 \%$ & $62,6 \%$ \\
\hline $30-34$ & $70,2 \%$ & $39,8 \%$ & $80,3 \%$ & $52,3 \%$ & $79,2 \%$ & $55,7 \%$ \\
\hline
\end{tabular}

Fuente: DGPNSD. Observatorio Español sobre Drogas, 2000.

Una de las consecuencias de este cambio de hábitos (que puede ser vista al mismo tiempo como una de las causas) es el fenómeno del botellón, que es contemplado por sus protagonistas como una solución al excesivo precio que se cobra por el alcohol en los bares, a la vez que como un tiempo y un espacio propios en los que se encuentran lejos de los adultos, gozando de una mayor movilidad para potenciar los encuentros interpersonales. En palabras de Calafat y colaboradores (2000a), "el botellón se ha convertido en una forma de acción colectiva, espontánea y no organizada". Pero, ¿en qué consiste exactamente el fenómeno del botellón? Para empezar podemos decir que se trata de un conjunto de reuniones periódicas de jóvenes, en espacios abiertos, donde el alcohol adquiere un papel protagonista. Todos los fines de semana, al caer la tarde, la mayoría de las ciudades españolas ven cómo grupos masivos de jóvenes, provistos de bolsas con bebidas alcohólicas compradas en comercios, ocupan sus plazas o calles con la intención de divertirse. La embriaguez se convierte, entonces, en el objetivo fundamental del tiempo libre juvenil.

Las causas que han propagado su realización son varias: por un lado, el consumo de alcohol realizado de esta manera les resulta más asequible, dada su limitada economía y los precios, cada vez más altos, de las bebidas alcohólicas en los diferentes bares, pubs o discotecas. Al mismo tiempo, al comprar la bebida ellos mismos en establecimientos comerciales aseguran su calidad, ya que el uso de garrafón comienza a ser moneda común en gran parte de los bares. Esta es una realidad a medias, ya que la mezcla de alcoholes baratos, de baja calidad, que suele realizarse en los botellones no parece que sea demasiado saludable. Por último, el botellón supone un ritual de grupo que responde a la necesidad del joven de crear un vínculo con su grupo de amigos, y de este grupo con el de otros semejantes, y que permite que este colectivo se sienta en un espacio propio, regido por sus propias normas, lejos del control y la mirada de los adultos.

La práctica del botellón viene generando una amplia polémica popular, siendo el centro de las iras y protestas vecinales, tanto por los ruidos incontrolables que genera hasta altas horas de la madrugada, allá donde tiene lugar, como por el rastro de suciedad y malos olores que ocasiona. La inquietud de la sociedad es indudable, si bien no alcanza la preocupación que suscita el uso de drogas de síntesis. Así, el 69,9 por ciento de la población española mayor de dieciocho años manifiesta estar preocupado $(42,8 \%)$ o muy preocupado (27,1\%) por el fenómeno del botellón (CIS, 2002). En cualquier caso, el 70 por ciento de los jóvenes admite que el botellón le ha originado problemas, siendo los más frecuentes las riñas, seguidos por discusiones con los padres o la pareja; a la hora de proponer soluciones, se engloban en dos posturas mayoritarias: los que creen que se necesita más información y una mayor oferta de actividades, y los que sentencian que "no hay alternativas" (Aguilera, 2000). 


\subsection{Las drogas ilegales}

Junto al consumo de alcohol, las noches de marcha conllevan en un sector de la población juvenil el uso recreativo de otro tipo de drogas que son ilegales, aunque no parece que la facilidad para adquirirlas y la generalización de su consumo se vean limitados por ello. Algunas de estas drogas van asociadas a una subcultura concreta, a un grupo determinado, como parte indispensable de su propia esencia, tan importante como el estilo a la hora de vestir o la música que se escucha. Así, el cannabis será un elemento primordial para un "rasta" y las pastillas lo serán para un "bakaladero". La utilización de diferentes drogas convierte en ocasiones al joven en una especie de zombie. Las drogas sintéticas en particular hacen girar al zombie en un absurdo baile sin final. "Piensa mientras bailas" rezaba el eslogan de un festival alternativo de música. Bonita frase, pero aterradora, si tenemos en cuenta su verdadero significado: ¡alguien debe recordarles a los chavales que piensen!

\subsubsection{Cannabis}

La droga ilegal más extendida entre los jóvenes es el cannabis. Su consumo está cercano ya a la legalidad de hecho, aunque no de derecho; no obstante, aún mantiene un halo de sustancia rebelde que hace que muchos jóvenes se identifiquen con ella. El consumo de cannabis en el último mes entre los jóvenes de 15 a 24 años es elevado (14,2\%), siendo mucho más alto entre los chicos $(18,1 \%)$ que entre las chicas $(10,1 \%)$, aunque estas diferencias son mayores en el consumo diario $(5,9 \%$ frente a $1,2 \%)$. No obstante, desde 1995 se han venido reduciendo progresivamente las diferencias entre los sexos, siendo un dato significativo que la Encuesta Domiciliaria de 1999 muestre como, por primera vez, en el grupo de edad de 15 a 19 años se igualan las prevalencias de consumo, tanto habitual como experimental. Al mismo tiempo, los datos ofrecidos por la Encuesta escolar sobre drogas revelan que los porcentajes de consumidores entre 14 y 18 años han crecido ininterrumpidamente desde 1994. Actualmente, la edad media de inicio en el consumo de cannabis se sitúa en los 18,4 años. Asimismo, la percepción que este grupo de jóvenes de la peligrosidad de esta droga ha disminuido con el tiempo, habiendo, en 2001, un 77,8 por ciento de estudiantes que piensan que el consumo habitual de cannabis puede causar muchos o bastantes problemas, mientras que tan sólo el 46,4 por ciento piensa que consumirlo alguna vez pude causar muchos o bastantes problemas.

El consumo de cannabis suele ser exclusivo del fin de semana, casi siempre unido al del alcohol, y no pocas veces al de la cocaína y el éxtasis, aunque existen ciertos círculos de jóvenes, en cualquier caso minoritarios, que mantienen durante el resto de la semana el uso, a escondidas, de este tipo de drogas, en ambientes en principio alejados de la concepción recreativa, como el instituto o la universidad, o, incluso, en sus propios hogares. La asociación entre consumo de cannabis y participación en la vida recreativa nocturna es más que evidente. A mayor consumo de cannabis, mayor consumo de otras drogas legales o ilegales, "mayor policonsumo y mayor participación en la vida nocturna". (Calafat y colaboradores, 2000b). Es un hecho demostrado que casi todos los consumidores de otras drogas más duras que el cannabis (más adictivas y peligrosas), han pasado en su mayoría por el consumo de ésta, pero también es cierto que el hecho de usar el cannabis de forma recreativa no conlleva necesariamente el uso de otras drogas más peligrosas.

\subsubsection{Cocaína}

A principios de los años noventa, cuando comienza a descender de forma leve pero constante el consumo de ciertas drogas, fundamentalmente la heroína, aunque también el LSD, las anfetaminas o el cannabis, parece que se produce un aumento del consumo de cocaína, que hasta entonces aún no se había extendido en España (Elzo y colaboradores, 1999). La cocaína en polvo es, junto a la heroína (20,7 años), la droga ilegal con una edad 
media más elevada de inicio en el consumo (20,3 años). Sin embargo, el consumo de heroína está prácticamente erradicado entre los jóvenes. Aunque el uso de cocaína es superior al uso de éxtasis en el conjunto de la población, no ocurre lo mismo entre la población más joven. Su uso recreativo está asociado a la búsqueda de placer y diversión con los amigos, mostrándose como una sustancia "fetiche" para algunas celebraciones importantes, y un "anzuelo para ligar" (Calafat y colaboradores, 2001). El 5 por ciento de los jóvenes de entre 15 y 29 años consumió cocaína en el último año. Los mayores porcentajes de consumo se dan entre los 20 y los 24 años, siendo un dato a destacar el hecho de que en el intervalo de edad de 15 a 19 años, las mujeres registren mayores prevalencias que los hombres. La población escolar ha venido incrementando en los últimos años el consumo experimental de cocaína, pasando de un 4,8 por ciento de jóvenes entre 15 y 19 años que afirma haber hecho uso de esta droga "alguna vez" en 1998, a un 5,4 por ciento en 2000. Los consumidores de cocaína suelen tener una menor percepción del riesgo asociado al consumo de drogas y una mayor frecuencia en los comportamientos de riesgo asociados a la conducción que los no consumidores (Calafat, Fernández y Juan, 2001).

\subsubsection{Drogas de síntesis}

Son varias las investigaciones que en los últimos años se han desarrollado en nuestro país, desde diferentes puntos de vista, con el objetivo de esclarecer los entresijos de la relevancia que han ido adquiriendo las drogas de síntesis en la sociedad española, fundamentalmente en la juventud (Cabrera Bonet y colaboradores, 1994; García Campos y Esteban Fernández, 1995; Valverde, 1997; GameIla y Álvarez Roldán, 1997, 1999; Bobes, Lorenzo, y Sáiz, 1998; Rubio y Álamo, 1998; Romo, 2001, etc). Bajo el nombre común de "drogas de síntesis", "sintéticas" o "de diseño", se agrupan una serie de sustancias psicoactivas de origen sintético, que suelen presentarse en forma de pastillas; la más difundida de ellas es la MDMA, conocida vulgarmente como "éxtasis". Los jóvenes utilizan diferentes formas propias para denominar a estas sustancias: "pastillas", "pastis", "pirulas", "tostis", "roscas", etc. Cada una de ellas lleva estampado un dibujo atractivo y posee un simpático nombre (Adán, Picapiedra, Popeye...), pudiendo ser de diferentes colores y formas, lo que las camufla bajo una apariencia inofensiva que realmente no es tal, al tiempo que aumenta la curiosidad de los jóvenes, haciendo que se identifiquen con los diferentes símbolos y estereotipos que representan.

Apenas se tiene noticia de este tipo de drogas antes de la década de los noventa. En toda Europa se incrementó el consumo de estas sustancias desde el año 1992 (Griffiths y Vingoe, 1997), dejando de ser considerado un producto contracultural, "ideologizado", para pasar a ser un producto de consumo masivo, utilizado por decenas de miles de usuarios (Gamella, Álvarez Roldán y Meneses, 1996). Tras un inicio elitista, minoritario y espontáneo, su consumo se extiende a partir de principios de los años noventa, bajo una impresión general de inocuidad, fundamentalmente al compararse con las drogas que venían consumiéndose y de las que sí se tenía conocimiento ya de su capacidad destructiva, en especial la heroína. Su consumo, además, se comienza a asociar, generalmente, a los ambientes lúdicos de fin de semana, a determinados tipos de música de baile, a cierto tipo de fiestas, así como a la diversión en grupo. Esto hace que su uso siga unas pautas muy homogéneas.

En la actualidad, el uso de drogas sintéticas es visto por muchos jóvenes como un elemento de afirmación frente a la sociedad, como una forma de integración y de participación social en determinadas subculturas. El Observatorio Español sobre Drogas, en sus últimas encuestas, encuentra "la diversión" como la motivación principal de los jóvenes a la hora de consumir pastillas (en un 46,1\%), si bien es seguida muy de cerca por la "experimentación de nuevas sensaciones" (en un $39,5 \%$ ) y por la motivación de "bailar" (en un 
22,9\%). La edad media de inicio en el consumo de éxtasis es a los 20 años. Muchos de los jóvenes comienzan a probar estas drogas, influenciados por otros miembros del grupo a los que pretenden emular o por una falta de seguridad personal, y ayudados por la facilidad para encontrarlas y lo asequible de su precio, lo hacen con la finalidad de experimentar una sensación nueva, por iniciarse en algo de lo que están oyendo hablar constantemente. Algunos de estos jóvenes apenas continuarán con su uso, mientras que otros lo utilizarán como un recurso recreativo durante un período de tiempo más o menos prolongado, habituando sus conductas lúdicas, principalmente del fin de semana, a la estimulación que este tipo de drogas les proporcionan. El perfil del consumidor de este tipo de sustancias es un joven de entre 18 y 24 años que usa esta droga en discotecas, durante los fines de semana, y que rara vez consume pastillas en solitario, mezclándolas por lo general con porros, cocaína, alucinógenos y, por supuesto, alcohol. A pesar de que durante años se divulgó la idea de que el consumo de drogas de síntesis limitaba el consumo de otras sustancias estupefacientes, realizándose únicamente acompañado de grandes cantidades de agua, lo cierto es que a medida que el uso de pastillas fue popularizándose, fue haciéndose cada vez más frecuente el uso combinado de otras drogas como el alcohol, el hachís o la cocaína, hasta el punto de que hoy día se habla de policonsumidores para referirse a los consumidores de drogas sintéticas. El policonsumo es el patrón típico de las drogas de síntesis. Según la Encuesta Domiciliaria de Población General de 1999, los consumidores de éxtasis son consumidores de hachís en un porcentaje del 93,1, de alcohol en un 91,4 y de cocaína en un 53 por ciento. En el caso del alcohol y, en bastante menor medida, del cannabis, sí que existe una población de consumidores que no mezcla estas sustancias con otras drogas.

También resulta un hecho destacable que los jóvenes que no consumen drogas de síntesis, en general, no muestren rechazo por los que sí lo hacen, lo que ejemplifica la nor- malidad que ha ido adquiriendo este tipo de consumos entre la juventud, su normalización. Su uso se banaliza, relacionándolo con estilos de vida muy extendidos. Además, la alarma social que las drogas generaban hace una década ha ido perdiendo intensidad, pese a que últimamente se esté empezando a tomar conciencia del peligro real que supone el consumo de las nuevas sustancias psicoactivas. Mientras en la población general el riesgo percibido ante el consumo de drogas de síntesis (el asumir que estas conductas pueden causar bastantes o muchos problemas) ha aumentado en los últimos años, en los estudiantes de 14 a 18 años ha disminuido, lo que sin duda debería hacernos reflexionar mucho sobre el riesgo que supone la baja percepción de los jóvenes respecto al peligro que representan las drogas de síntesis. Además de los indudables riesgos que estas drogas tienen para la salud, tanto a corto como a largo plazo, un riesgo añadido son los accidentes de circulación, pues en muchas ocasiones las fiestas donde se reúnen los jóvenes consumidores de pastillas son a las afueras de las ciudades, en grandes naves o discotecas, y se desplazan hasta ellas en sus motos o coches (la relación entre los accidentes de tráfico y el consumo de alcohol y drogas en los jóvenes, que frustra tantas vidas, familias e ilusiones, resulta una de las más trágicas lacras de los últimos tiempos, y merece, en sí misma, un espacio del que aquí no disponemos).

En cuanto a la situación actual, parece ser que el número de usuarios de drogas de síntesis está empezando a estancarse; el consumo de éxtasis se ha estabilizado ya en el conjunto de la sociedad. Sin embargo, el consumo experimental entre los jóvenes de 14 a 18 años se ha incrementado $y$, entre los hombres de 15-34 años la prevalencia de consumo durante los últimos 12 meses ha pasado del 2,3 por ciento en 1999 al 6,8 en 2001. La última Encuesta sobre drogas a población escolar muestra que el 2,9 por ciento de los jóvenes españoles de entre 15 y 16 años admite haber ingerido éxtasis alguna vez en su vida. Habrá, pues, que esperar para com- 
probar si el grado de consumo de estas sustancias, que venía creciendo desde su incursión en nuestras sociedades, ha alcanzando su cota más alta, o si, por el contrario, nos enfrentamos con un problema que continúa acrecentándose.

\section{CONCLUSIONES}

Tras el análisis llevado a cabo sobre el uso del tiempo libre por parte de la población juvenil española, así como sobre sus tendencias en el uso de drogas recreativas, podemos concluir que el ocio juvenil ha venido transformando su naturaleza en los últimos años, delimitando la noche como esfera de esparcimiento y la calle como espacio en el que se desarrolla la mayor parte de la actividad recreativa. En la actualidad, el consumo recreativo de drogas (legales e ilegales) se ha convertido en una práctica común de muchos jóvenes españoles. Aunque en los últimos años también venía siendo habitual este tipo de comportamientos, últimamente parece haber tomado mayor relevancia, existiendo una serie de transformaciones importantes tanto en la forma en que se consumen estas sustancias, como en las propias sustancias consumidas. En estas nuevas formas de consumo sobresalen dos fenómenos tan característicos y problemáticos como el botellón y el consumo de drogas de síntesis. Cabe destacar, asimismo, el auge que ha experimentado y continúa experimentando el consumo femenino de alcohol y drogas, que tiende a igualar al de los varones. Por último, uno de los mayores problemas con los que nos enfrentamos es que la juventud actual percibe estas sustancias como carentes de riesgos para la salud, atribuyéndoles, al mismo tiempo, un marcado valor sociogénico.

\section{REFERENCIAS}

Aguilera, R. (2002) Generación botellón. Madrid: Oberon.

Aguinaga, J.; Comas, D. (1997) Cambios de hábito en el uso del tiempo. Madrid: Instituto de la Juventud, Ministerio de Trabajo y Asuntos Sociales.

Agulló Tomás, E. (1997) Jóvenes, trabajo e identidad. Oviedo: Servicio de Publicaciones de la Universidad de Oviedo.

Álvaro, J.L. (1992) Desempleo y bienestar psicológico. Madrid: Siglo XXI.

Bobes, J.; Lorenzo, P.; Sáiz, P. (eds.) (1998) Éxtasis: Un abordaje comprehensivo. Barcelona: Masson.

Bobes, J.; Calafat, A. (eds.) (2000) Monografía Cannabis. Vol. 12, suplemento 2.

Cabrera Bonet et al. (1994) Éxtasis: ¿una droga sin problemas? Madrid: Ed. Ela.

Calafat, A. et al. (1993) Malestar juvenil, estilos de vida y consumo de drogas. MIMEO.

Calafat, A. et al. (2000a) Salir de marcha y consumo de drogas. Madrid: Plan Nacional sobre Drogas.

Calafat, A. et al. (2000b) "Consumo y consumidores de cannabis en la vida recreativa". Vol. 12, suplemento 2. Pp. 197-230.

Calafat, A. et al. (2001) "Vida social de la cocaína". Adicciones. Vol. 13, suplemento 2. Pp. 61-104.

Calafat, A.; Fernández, C.; Juan, M. (2001) "Uso recreativo de cocaína y asunción de riesgos: resultados convergentes en cuatro muestras". Adicciones. Vol. 13, suplemento 2. Pp. 123146.

CIS -Centro de Investigaciones Sociológicas(2002) Barómetro de Marzo. Estudio núm. 2.452 .

CIS -Centro de Investigaciones Sociológicas(1999) "Los jóvenes de hoy". Datos de opinión. Núm. 19.

CIS -Centro de Investigaciones Sociológicas(2000) "Vida cotidiana de los jóvenes". Datos de opinión. Núm. 23.

Comas, D. (1994) Los jóvenes y el uso de drogas en la España de los años 90. Instituto de la Juventud, Ministerio de Asuntos Sociales.

Comas, D. (2001) La evaluación de los programas de ocio alternativo de fin de semana. 
Madrid: Instituto de la Juventud, Ministerio de Trabajo y Asuntos Sociales.

Costa, P.; Pérez Tornero, J.M.; Tropea, F. (1996) Tribus urbanas. Paidós. Barcelona.

De Miguel, A. (1990) Los españoles. Madrid: Temas de hoy.

De Miguel, A. (2000) Dos generaciones de jóvenes: 1960-1998. Instituto de la Juventud, Ministerio de Trabajo y Asuntos Sociales.

Elzo, J. (1998) “Los adolescentes y sus valores en la sociedad española actual". Proyecto Hombre. Vol. 25.

Elzo, J. et al. (1999) Jóvenes españoles 99. Madrid: Fundación Santa María.

Elzo, J. (2000) El silencio de los adolescentes. Madrid: Temas de Hoy.

Encinas Garza, J. (1994) Bandas juveniles. México: Editorial Trillas.

Gamella, J.F; Álvarez Roldán, A.; Meneses, C. (1996) "Drogas de síntesis en España. Datos de una investigación antropológica". XXIII Jornadas Nacionales de Socidrogalcohol. Oviedo.

Gamella, J.F.; Álvarez Roldán, A. (1997) Drogas de síntesis. Pautas y tendencias de su adquisición y consumo. Un estudio en cuatro Comunidades Autónomas. Madrid: Delegación del Gobierno, Ministerio del Interior.

Gamella, J.F.; Álvarez Roldán. A. (1999) Las rutas del éxtasis. Drogas de síntesis y nuevas culturas juveniles. Barcelona: Ariel.

García Campos, L.; Esteban Fernández, J.M. (1995) Drogas sintéticas y nuevos patrones de consumo. Madrid: Coordinadora de ONGs que intervienen en drogodependencias.

Gil Calvo, E. et al. (1985) Ocio y prácticas culturales de los jóvenes. Informe Juventud en España. Madrid: Instituto de la Juventud, Ministerio de Cultura.

Griffiths, P.; Vingoe, L. (1997) The use of amphetamines, ecstasy and LSD in the European Community: a review of data on consumption patterns and current epidemiological literature. Londres: National Addiction Centre.

Gual, A. (ed.) (2002) Monografía Alcohol. Adicciones. Vol 14, suplemento 1.

Gutiérrez Puebla, J. et al. (2001) “El perfil de los consumidores en los grandes centros comerciales y de ocio de los alrededores de Madrid". Boletín de la A.G.E.. Núm. 31. Pp. 61-85.
Hernán M.; Ramos M.; Fernández A. (2002) Salud y Juventud en España 2001. Madrid: Consejo de la Juventud de España.

Iglesias de Ussel, J. (1997) “La movida: un análisis sociológico". Movida y Sociedad. Pp. 61-77.

INJUVE (2001) Sondeo periódico de opinión y situación de la gente joven. Primer, segundo, tercer y cuarto trimestre 2002. Madrid: Instituto de la Juventud.

INJUVE (2002) Sondeo periódico de opinión y situación de la gente joven. Primer, segundo y tercer trimestre 2002. Madrid: Instituto de la Juventud.

Laespada, M.T.; Salazar, L. (1999) "Las actividades no formalizadas de los jóvenes". En Elzo, J. et al. Jóvenes españoles 99. Madrid: Fundación Santa María

Laespada, M.T. (1999) "Alcohol y tabaco". En Elzo, J. (dir) Las culturas de las drogas en los jóvenes: ritos y fiestas. San Sebastián: Servicio de publicaciones del Gobierno Vasco.

Linz, J.; Stephan, A. (1996) Problems of Transition and Democratic Consolidation. Baltimore: Jhon Hopkins University Press.

Maffesoli, M. (1990) El tiempo de las tribus. Barcelona: Icaria.

Martín Serrano, M.; Velarde, O. (1997) Informe de Juventud en España. Madrid: Instituto de la Juventud, Ministerio de Trabajo y Asuntos Sociales.

Martín Serrano, M.; Velarde, O. (2000) Informe de Juventud en España. Madrid: Instituto de la Juventud, Ministerio de Trabajo y Asuntos Sociales.

Martín Serrano, M. (1994) Historia de los cambios de mentalidad de los jóvenes entre 19601990. Instituto de la Juventud, Ministerio de Trabajo y Asuntos Sociales.

Munné, F; Codina, N. (1996) "Psicología Social del ocio y el tiempo libre". En Álvaro, J.L.; Garrido, A.; Torregrosa, J.R. Psicología Social Aplicada. Madrid: McGraw-Hill.

Navarro, M. (1993) "Juventud". En Del Campo, S. Tendencias sociales en España (1960-1990). Bilbao: Fundación BBV.

Navarro, J. (2000) El consumo de alcohol y otras drogas en el colectivo femenino. Madrid: Instituto de la Mujer, Ministerio de Trabajo y Asuntos Sociales. 
Navarro, M.; Mateo, M.J. (1993) Informe Juventud en España. Madrid: Instituto de la Juventud, Ministerio de Asuntos Sociales.

Núñez Pérez, A.; Soto Carballada, D.; Castro Pastor, A. (1998) Consumo de drogas en España: reflexiones sobre sus tendencias epidemiológicas y sociales. Psiquiatría Pública. Vol. 10, número 6. Pp. 15-20.

Observatorio Español sobre Drogas (1997) Encuesta sobre drogas a población escolar, 1996. Madrid: Delegación del Gobierno, Ministerio del Interior.

Observatorio Español sobre Drogas (1996) Encuesta Domiciliaria sobre Consumo de Drogas en España, 1995. Madrid: Delegación del Gobierno, Ministerio del Interior.

Observatorio Español sobre Drogas (1998) Encuesta Domiciliaria sobre Consumo de Drogas en España, 1997. Madrid: Delegación del Gobierno, Ministerio del Interior.

Observatorio Español sobre Drogas (1999) Encuesta sobre drogas a población escolar, 1998. Madrid: Delegación del Gobierno, Ministerio del Interior.

Observatorio Español sobre Drogas (2000) Encuesta Domiciliaria sobre Consumo de Drogas en España,1999. Madrid: Delegación del Gobierno, Ministerio del Interior.

Observatorio Español sobre Drogas (2001) Encuesta sobre drogas a población escolar, 2000. Madrid: Delegación del Gobierno, Ministerio del Interior.

Observatorio Español sobre Drogas (2002) Encuesta Domiciliaria sobre Consumo de Drogas en España, 2001. Madrid: Delegación del Gobierno, Ministerio del Interior.

Olivera, J. (1995) "Las actividades físicas de aventura en la naturaleza: análisis sociocultural". Apunts: Educación Física y Deportes. Vol 41. Pp. 5-9.

Orizo, F.A. (1996) Sistema de valores en la España de los 90. Madrid: Colección Monografías, C.I.S

Pascual, F. (2002) "Percepción del alcohol entre los jóvenes". Adicciones. vol. 14, suplemento 1. Pp. 123-132.

Pascual, F; Torres, M.; Calafat, A. (eds.) (2001) Monografía cocaína. Adicciones. Vol 13, suplemento 2 .

Prieto Lacaci, R. (1998) Tendencias del Asociacionismo Juvenil en los años 90. Madrid: Institu- to de la Juventud, Ministerio de Trabajo y Asuntos Sociales.

Rizter, G. (1996) La McDonalización de la sociedad. Un análisis de la racionalización de la vida cotidiana. Barcelona: Ariel.

Rodríguez, J. (2000) El ocio de los universitarios. Una aproximación psicosociológica al estilo de vida universitario en la sociedad contemporánea. Tesis Doctoral. Oviedo: Facultad de Psicología, Universidad de Oviedo.

Rodríguez, J.; Agulló, E. (1999) “Estilos de vida, cultura, ocio y tiempo libre de los estudiantes universitarios". Psicothema. Vol. 11, núm. 2. Pp. 247-259.

Rodríguez, J.; Agulló, E. (2002) "Psicología social y ocio: Una articulación necesaria". Psicothema. Vol. 14, núm. 1. Pp. 124-133.

Romo, N. (2001) Mujeres y drogas de diseño. Género y riesgo en la cultura del baile. San Sebastián: Tercera Prensa.

Rubio, G; Álamo, C. (1998) Éxtasis (MDMA). Una droga para la controversia, Valencia: Promolibro.

Ruiz Olabuénaga, J.I. (ed.) (1996) Vida Cotidiana y Nuevas Generaciones. Bilbao: Universidad de Deusto.

Ruiz Olabuénaga, J.L. (dir.) (1998) La juventud liberta. Género y estilos de vida de la juventud urbana española. Bilbao: Fundación BBV.

Salazar, D. (2000) El adolescente. México: Dulanto McGraw-Hill Interamericana.

Sánchez, L. (2002) "Consumo de alcohol en la población juvenil". Adicciones. Vol. 14, suplemento 1. Pp. 99-114.

Secades R. (1996) Alcoholismo juvenil. Madrid: Pirámide.

Secades, R. (1998) "Uso y abuso del alcohol en los jóvenes". Revista Electrónica Iberoamericana de Psicología Social (R.E.I.P.S.). Universidad de Oviedo. Disponible en: http://www.uniovi. es/ Psi/REIPS.

Setién, M.L. (1994) "Ocio y calidad de vida". En EI País (28-7-94)

Valverde, M.A. (1997) Aproximación al consumo de pastillas y drogas de diseño en ambientes juveniles. Propuestas de intervención. Pamplona: Servicio Navarro de Salud, Subdirección de Salud Mental.

Zamora Acosta, E. (1993) Jóvenes andaluces de Ios 90. Sevilla: Junta de Andalucía, Consejería 
de Asuntos Sociales, Dirección General de Juventud, Escuela Pública de Animación Sociocultural.

Zárraga, J.L. (1985) Informe Juventud en España 1984. La inserción de los jóvenes en la sociedad. Madrid: Instituto de la Juventud, Ministerio de Cultura.

Zárraga, J.L. (1989) Informe de juventud en España 1988. Madrid: Instituto de la Juventud, Ministerio de Cultura. 
